\title{
COVID-19 and Aspiration Pneumonia: Similar Pulmonary Findings with Different Diagnoses—a Pitfall in [18F]FDG PET/CT
}

\author{
Virginia Liberini ${ }^{1}$ (D) Serena Grimaldi ${ }^{1} \cdot$ Martin W. Huellner ${ }^{2} \cdot$ Francesca Giunta ${ }^{1} \cdot$ Costanza Bachi $^{1}$. \\ Sara Dall'Armellina ${ }^{1}$ - Federica Onesti ${ }^{1}$ - Francesco Ceci ${ }^{1}$ - Carola Boccomini ${ }^{3}$ - Massimiliano Icardi $^{4}$. \\ Désirée Deandreis ${ }^{1}$
}

Accepted: 18 July 2021 / Published online: 29 July 2021

(C) The Author(s) 2021

\begin{abstract}
Since December 2019, the severe acute respiratory syndrome coronavirus 2 (SARS-CoV-2) has become a worldwide pandemic. Especially in the centers most affected by the pandemic, symptoms (such as fever, cough, myalgia, or fatigue) and/or radiological signs (such as ground-glass opacity) typically related to COVID-19 often diverted clinicians' attention from other diseases. Despite the urgency to recognize and cure SARS-CoV-2 infection, a plethora of differential diagnoses must be considered, and other diseases must be equally and promptly treated, as described in this case report.
\end{abstract}

Keywords [18F]FDG PET/CT · COVID-19 $\cdot$ Pneumonia $\cdot$ Ab ingestis $\cdot$ Aspiration pneumonia $\cdot$ SARS-CoV-2

\section{Introduction}

The severe acute respiratory syndrome coronavirus 2 (SARSCoV-2) has become a worldwide pandemic. The infective illness (COVID-19) may vary from asymptomatic disease to life-threatening pneumonia [1-3].

Computed tomography (CT) plays a key role in detecting COVID-19 pneumonia [4]. Moreover, few cases have been detected incidentally by ${ }^{18} \mathrm{~F}$-fuorodeoxyglucose ([18F]FDG) positron emission tomography (PET)/CT [5-7].

Despite their high sensitivity, CT and PET/CT findings are unspecific and may overlap with other diseases [8] and may mislead from the right diagnosis, challenging the differential

This article is part of the Topical Collection on Covid-19

Virginia Liberini

virginia.liberini@unito.it

1 Nuclear Medicine Unit, Department of Medical Sciences, University of Turin, Corso Dogliotti 14, 10126 Turin, Italy

2 Department of Nuclear Medicine, University Hospital Zurich, Rämistrasse 100, CH-8091 Zurich, Switzerland

3 Hematology Unit, Città della Salute e della Scienza University and Hospital, Turin, Italy

4 2nd Medical Oncology Division, Città della Salute e della Scienza, Turin, Italy diagnosis and delaying the correct individual patient management for physicians.

We present two asymptomatic, immunocompromised [18F]FDG PET/CT patients from a hospital in a COVID-19 hotspot, having similar lung findings suspicious for COVID19 pneumonia - one of which was false positive.

\section{Case Report}

Patient 1 is an asymptomatic 80-year-old man with a history of non-Hodgkin lymphoma who underwent [18F]FDG PET/ $\mathrm{CT}$ after the end of immunochemotherapy in March 2020.

Compared with the previous PET/CT scan (Fig. 1a), the current PET/CT (Fig. 1b) showed resolution of mediastinal lymph node uptake (black arrow). However, PET/CT and CT images (Fig. 1c-1) revealed the appearance of multiple bilateral FDG-avid ground-glass opacities (GGOs, yellow arrows), with a predominantly peripheral distribution in the posterior segments of the inferior lung lobes. Moreover, new mildly increased uptake was seen in several mediastinal lymph nodes, without enlargement on CT images (Fig. 1b, red arrow).

Ground-glass opacities are the most common CT finding in COVID-19 pneumonia, particularly in the early phase of the disease, especially in asymptomatic patients [9]. The pattern is usually multifocal, bilateral, and peripheral, with a posterior 

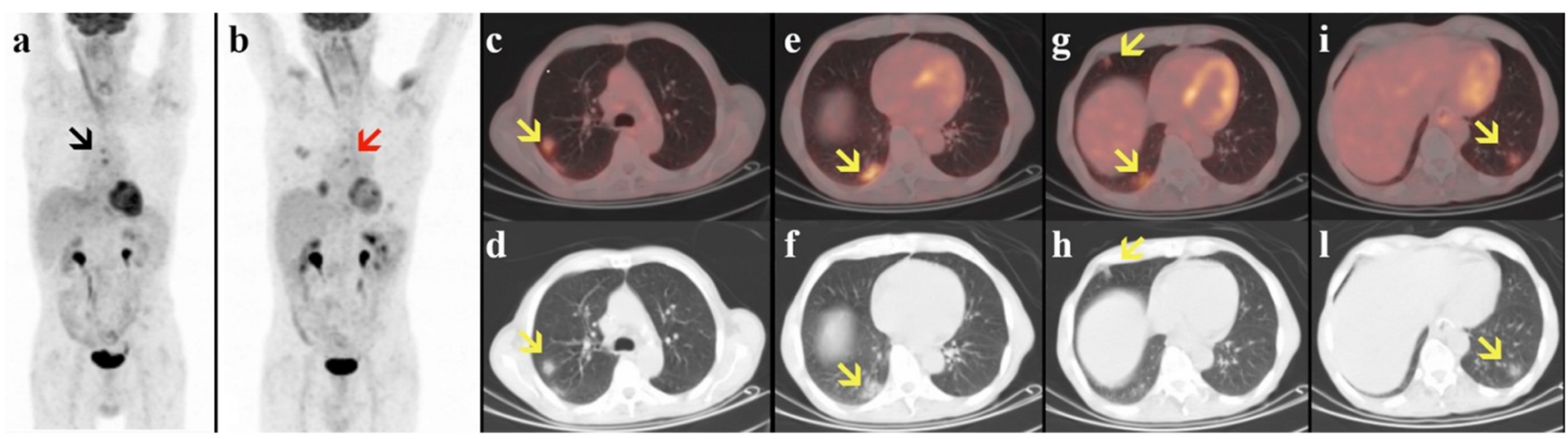

Fig. 1 Previous (a) and current (b-l) [18F]FDG PET/CT of an asymptomatic 80-year-old man with a history of non-Hodgkin lymphoma. Maximum intensity projection $(\mathbf{a}-\mathbf{b})$, transaxial fused PET/CT $(\mathbf{c}, \mathbf{e}, \mathbf{g}, \mathbf{i})$, and CT $(\mathbf{d}, \mathbf{f}, \mathbf{h}, \mathbf{l})$ images of [18F]FDG uptake in the lungs

distribution, mainly in the lower lobes, while enlarged mediastinal or hilar lymph nodes are not typically observed [4, 10, $11]$.

FDG uptake has been described in COVID-19 pneumoniarelated GGOs in both symptomatic and asymptomatic patients $[5,6,12,13]$, as well as in mediastinal lymph nodes [14].

Due to these findings, the patient was counseled, and isolation procedures and scanner sanitation measures were started. The gold standard for the diagnosis of COVID-19 infection, a reverse transcriptase-polymerase chain reaction (RT-PCR) test from pharyngeal swabs, was subsequently performed and confirmed the diagnosis of COVID-19 [1, 15].

Patient 2 is an asymptomatic 51-year-old man with a history of oral cavity squamous cell carcinoma, associated swallowing difficulties, and repetitive aspiration pneumonia, previously treated by surgery, chemotherapy, and immunotherapy, who underwent $[18 \mathrm{~F}] \mathrm{FDG}$ PET/CT for restaging in March 2020.

Follow-up PET/CT (Fig. 2b) showed a good partial metabolic response of the primary tumor (black arrows) compared with the baseline scan (Fig. 2a). However, PET/CT showed the appearance of few bilateral GGOs (yellow arrows) in the posterior segments of the inferior lung lobes (Fig. $2 \mathrm{c}-\mathrm{h}$ ) associated with hilar and mediastinal lymph nodes (Fig. 2b, red arrow), both mildly FDG-avid.

Due to these findings suspicious for COVID-19, the patient was counseled, and isolation and sanitation measures were triggered. The patient was quarantined at home with adequate clinical monitoring. After 2 days, he developed fever $>38^{\circ} \mathrm{C}$, which resolved spontaneously. RT-PCR for SARS-CoV-2 was negative in two consecutive tests.

In this patient, considering the clinical history, [18F]FDG $\mathrm{PET} / \mathrm{CT}$ findings matched aspiration pneumonia, mimicking COVID-19 infection [16, 17].

\section{Discussion}

The SARS-CoV-2 pandemic has a considerable impact on nuclear medicine departments worldwide, and also falsepositive cases may entail enormous efforts. While several articles have reported and suggested potential clinical usefulness of [18F]FDG PET/CT in patients with suspected COVID-19 infection, especially at early stages when clinical symptoms are nonspecific, only Treglia recently emphasized the risk of
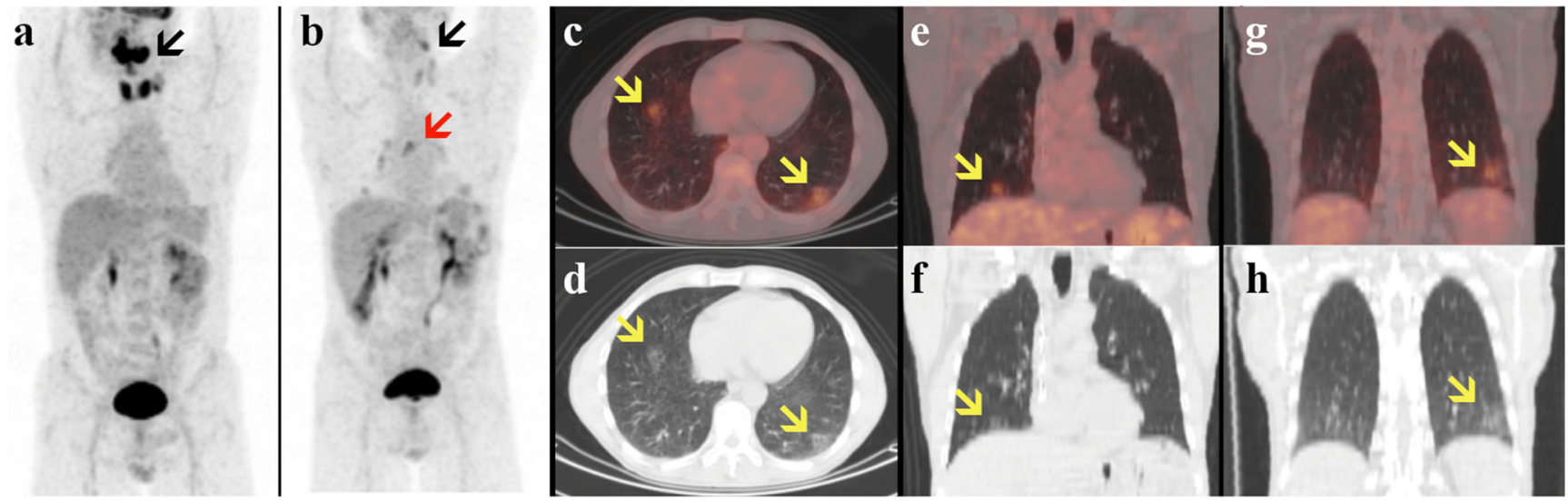

Fig. 2 Previous (a) and current (b-l) [18F]FDG PET/CT of an asymptomatic 51-year-old man with a history of oral cavity squamous cell carcinoma. Maximum intensity projection (a-b), transaxial and coronal fused PET/CT (c, e, g), and CT (d, f, h) images of [18F]FDG uptake in the lungs 
considering these findings as a "peculiar metabolic behavior of this infection" [18].

Different conditions, both infectious and noninfectious, are responsible for bilateral lung parenchymal involvement, developing either as focal or diffuse lung disease. Most of these diseases are characterized by an increased tropism for glucose by inflammatory cells recalled and activated by the infectious process or by tumor cells, translating into an increased uptake of [18F]FDG related to the increased glucose metabolism. PET/CT with [18F]FDG helps the characterization of these pathological processes; however, some of these, especially in the early stages of disease, may be difficult to distinguish from each other. Several studies have highlighted the few differences present radiologically and metabolically between COVID-19 infection and other viral pneumonias: COVID-19 pneumonia is more likely to have a peripheral distribution ( $80 \%$ vs. $57 \%$ ), ground-glass opacity ( $91 \%$ vs. $68 \%$ ), and fine reticular opacity ( $56 \%$ vs. $22 \%$ ), but less likely to have a central plus peripheral distribution (14\% vs. $35 \%)$ and pleural effusion (4\% vs. 39\%) [19-21].

However, to the best of our knowledge, there is currently no evidence in the literature regarding the radiological and metabolic differences between COVID-19 and aspiration pneumonia. Aspiration pneumonia presents on [18F]FDG $\mathrm{PET} / \mathrm{CT}$ with different patterns, usually very striking, as this clinical condition often leads to severe over-infection, with the development of lobar or segmental pneumonia, bronchopneumonia, lung abscess, and empyema. Frequently, PET/CT shows increased diffuse, intense, and bilateral uptake especially in the posterior segment of the upper lobes and the superior segment of the lower lobes, which may mimic other FDGavid pulmonary diseases. Nevertheless, in some cases, especially if diagnosed early, aspiration pneumonia may occur only with unilateral or bilateral ground glass, especially in cases of diffuse aspiration bronchiolitis in patients with esophageal conditions such as achalasia, Zenker's diverticulum, or carcinoma of the oral cavity, especially esophageal, associated with dysphagia, regurgitation, and aspiration [22].

Therefore, there is currently no scientific evidence about the usefulness of [18F]FDG PET/CT in the evaluation of COVID-19 pneumonia, as metabolic behavior of this infection is not pathognomonic, but rather nonspecific. On the other hand, one should be more careful about the not remote possibility of identifying with [18F]FDG PET/CT an interstitial pneumonia (with ground-glass opacity) suspected of COVID-19 infection [18].

To the best of our knowledge, this report is the first to present a concrete example of the lack of specificity of PET/ CT findings in COVID-19 pneumonia comparing to aspiration pneumonia. In case of PET/CT findings suggestive for COVID-19 pneumonia, asymptomatic patients should be carefully monitored or tested with RT-PCR, but at the same time, the differential diagnosis must be considered.
This case highlights how differential diagnosis on imaging remains a challenge, with the additional reason of providing proper individual patient management and avoiding overload of the COVID-19 surveillance system.

Acknowledgements The authors would like to thank primary care physicians, Dr. Paolo Di Taranto and Dr. Alberto Mazzilo, for patient management and collaboration.

Author Contribution DD designed the study; VL, SG, MWH, and DD wrote the manuscript; FO, FG, CB, SD, FC, $\mathrm{CB}$, and MI contributed to collect the data and the images and commented on the manuscript. All authors reviewed the final manuscript.

Funding Open access funding provided by Università degli Studi di Torino within the CRUI-CARE Agreement.

Data availability Not applicable. Code Availability Not applicable.

\section{Declarations}

Ethics Approval All procedures performed in studies involving human participants were in accordance with ethical standards of the institutional and/or national committee and with the 1964 Helsinki declaration and its later amendments or comparable ethical standards. The use of the data of these two patients was approved by AOU Città della Salute e della Scienza di Torino Ethics Committee.

Consent to Participate Informed consent was obtained from all individual participants included in the study prior to imaging procedures.

Consent for Publication Not applicable.

Conflict of Interest The authors declare no competing interests.

Open Access This article is licensed under a Creative Commons Attribution 4.0 International License, which permits use, sharing, adaptation, distribution and reproduction in any medium or format, as long as you give appropriate credit to the original author(s) and the source, provide a link to the Creative Commons licence, and indicate if changes were made. The images or other third party material in this article are included in the article's Creative Commons licence, unless indicated otherwise in a credit line to the material. If material is not included in the article's Creative Commons licence and your intended use is not permitted by statutory regulation or exceeds the permitted use, you will need to obtain permission directly from the copyright holder. To view a copy of this licence, visit http://creativecommons.org/licenses/by/4.0/.

\section{References}

1. Rodriguez-Morales AJ, Cardona-Ospina JA, Gutiérrez-Ocampo E, et al. Clinical, laboratory and imaging features of COVID-19: a systematic review and meta-analysis. Travel Med Infect Dis. Elsevier USA. 2020. Available from: https://doi.org/10.1016/j. tmaid.2020.101623

2. Li Q, Guan X, Wu P, et al. Early transmission dynamics in Wuhan, China, of novel coronavirus-infected pneumonia. N Engl J Med 
[Internet]. NLM (Medline); 2020 [cited 2020];382:1199-1207. Available from: https://doi.org/10.1056/NEJMoa2001316

3. Dhama K, Khan S, Tiwari R, et al. Coronavirus disease 2019COVID-19. Clin Microbiol Rev [Internet]. American Society for Microbiology; 2020 [cited 2020];33:1-48. Available from: /pmc/ articles/PMC7405836/?report=abstract

4. Salehi S, Abedi A, Balakrishnan S, et al. Coronavirus disease 2019 (COVID-19): a systematic review of imaging findings in 919 patients. Am J Roentgenol [Internet]. 2020 [cited 2020];1-7. Available from: www.ajronline.org

5. Qin C, Liu F, Yen TC, et al. 18F-FDG PET/CT findings of COVID19: a series of four highly suspected cases. Eur J Nucl Med Mol Imaging. Springer. 2020;47. Available from: https://doi.org/10. 1007/s00259-020-04734-w

6. Albano D, Bertagna F, Bertolia M, et al. Incidental findings suggestive of COVID-19 in asymptomatic patients undergoing nuclear medicine procedures in a high prevalence region. J Nucl Med [Internet]. J Nucl Med; 2020 [cited 2020]; Available from: http:// www.ncbi.nlm.nih.gov/pubmed/32238429

7. Tulchinsky M, Fotos JS, Slonimsky E. Incidental CT findings suspicious for Covid-19 associated pneumonia on nuclear medicine exams: recognition and management plan. Clin Nucl Med [Internet]. Clin Nucl Med; 2020 [cited 2020];1. Available from: http://www.ncbi.nlm.nih.gov/pubmed/32282404

8. Bai HX, Hsieh B, Xiong Z, et al. Performance of radiologists in differentiating COVID-19 from viral pneumonia on chest CT. Radiology [Internet]. Radiological Society of North America (RSNA); 2020 [cited 2020];200823. Available from: https://doi. org/10.1148/radiol.2020200823

9. Inui S, Fujikawa A, Jitsu M, et al. Chest CT findings in cases from the cruise ship "diamond princess" with coronavirus disease 2019 (COVID-19). Radiol Cardiothorac Imaging [Internet]. Radiological Society of North America (RSNA); 2020 [cited 2020];2:e200110. Available from: https://doi.org/10.1148/ryct.2020200110

10. Kanne JP. Chest CT Findings in 2019 Novel Coronavirus (2019nCoV) Infections from Wuhan, China: Key Points for the Radiologist. Radiology. 2020 Apr;295(1):16-17. Available from: https://doi.org/10.1148/radiol.2020200241

11. Chung M, Bernheim A, Mei X, et al. CT imaging features of 2019 novel coronavirus (2019-NCoV). Radiology. Radiological Society of North America Inc. 2020;295:202-7.

12. Zou S, Zhu X. FDG PET/CT of COVID-19. Radiology. Radiological Society of North America (RSNA). 2020:200770. Available from: https://doi.org/10.1148/radiol.2020200770
13. Joob, B., Wiwanitkit, V. 18F-FDG PET/CT and COVID-19. Eur J Nucl Med Mol Imaging47, 1348 (2020). Available from: https://doi. org/10.1007/s00259-020-04762-6

14. Deng, Y., Lei, L., Chen, Y. et al. The potential added value of FDG PET/CT for COVID-19 pneumonia. Eur J Nucl Med Mol Imaging47, 1634-1635 (2020). Available from: https://doi.org/10. 1007/s00259-020-04767-1

15. Lan L, Xu D, Ye G, et al. Positive RT-PCR test results in patients recovered from COVID-19. JAMA, J Am Med Assoc. American Medical Association. 2020. Available from: doi:10.1001/ jama.2020.2783

16. Scheeren B, Gomes E, Alves G, et al. Chest CT findings in patients with dysphagia and aspiration: a systematic review. J Bras Pneumol [Internet]. 2017 [cited 2020];43:313-318. Available from: https:// www.ncbi.nlm.nih.gov/pmc/articles/PMC5687969/

17. Komiya K, Ishii H, Umeki K, Kawamura T, Okada F, Okabe E, et al. Computed tomography findings of aspiration pneumonia in 53 patients. Geriatr Gerontol Int. Geriatr Gerontol Int. 2013;13:580-5.

18. Treglia G. The role of 18F-FDG PET for COVID-19 infection: myth versus reality [Internet]. Clin. Transl. Imaging. Springer; 2020 [cited 2020]. page 125-126. Available from: https:// pubmed.ncbi.nlm.nih.gov/32355659/

19. Jin C, Luo X, Qian S, et al. Positron emission tomography in the COVID-19 pandemic era. Eur J Nucl Med Mol Imaging [Internet]. Nature Publishing Group; 2021 [cited 2021];1. Available from: https://doi.org/10.1007/s00259-021-05347-7

20. Bai HX, Hsieh B, Xiong Z, et al. Performance of radiologists in differentiating COVID-19 from non-COVID-19 viral pneumonia at chest CT. Radiology [Internet]. Radiological Society of North America Inc.; 2020 [cited 2021];296:E46-E54. Available from: https://pubmed.ncbi.nlm.nih.gov/32155105/

21. Annunziata S, Delgado Bolton RC, Kamani CH, et al. Role of 2[18F]FDG as a radiopharmaceutical for PET/CT in patients with covid-19: a systematic review [Internet]. Pharmaceuticals. MDPI AG; 2020 [cited 2021]. page 1-11. Available from: https:// pubmed.ncbi.nlm.nih.gov/33182811/

22. Franquet T, Giménez A, Rosón N, et al. Aspiration diseases: findings, pitfalls, and differential diagnosis. Radiographics [Internet]. Radiological Society of North America Inc.; 2000 [cited 2021];20: 673-685. Available from: https://pubmed.ncbi.nlm.nih.gov/ $10835120 /$

Publisher's Note Springer Nature remains neutral with regard to jurisdictional claims in published maps and institutional affiliations. 